\title{
Efecto Peltzman al estilo peruano: el derecho y la economía de los llamados a revisión de productos defectuosos $\left.{ }^{*}\right)$
}

Peltzman effect peruvian style: the law and economics of recalls for defective
products

Gustavo Rodríguez García ${ }^{(* *)}$

Rodríguez García Consultoría Especializada (Lima, Perú)

Mariana García Miró Basadre ${ }^{(* *)}$

CPB Abogados (Lima, Perú)

Resumen: El sistema legal plantea dramáticos ejemplos de consecuencias no pretendidas y, en particular, el sistema de protección al consumidor. En el presente trabajo, los autores analizan los incentivos perversos que un pobre diseño de las reglas sobre llamados a revisión de productos defectuosos puede generar. Así, una genuina preocupación por las consecuencias aconseja introducir modificaciones orientadas a lograr el bienestar del consumidor.

Palabras clave: Efecto Peltzman - Derecho y Economía - Consumidor - Consecuencias no pretendidas - Análisis Económico del Derecho

\begin{abstract}
The legal system introduces dramatic examples of unintended consequences and the consumer protection system. In this paper, the authors analyze the perverse incentives that a poor design of the rules on recalls to review defective products can generate. Thus, a genuine concern about the consequences advises introducing modifications aimed at achieving consumer welfare.
\end{abstract}

Keywords: Peltzman Effect - Law and Economics - Consumer - Unintended consequences - Law and Economics

$\left({ }^{*}\right) \quad$ Nota del Editor: este artículo fue recibido el 5 de abril de 2020 y su publicación fue aprobada el 17 de mayo de 2020.

$\left(^{* *}\right.$ Abogado por la Pontificia Universidad Católica del Perú. Magíster por la Universidad Austral de Argentina. Doctorando en Ciencias Jurídicas por la Pontificia Universidad Católica de Argentina. Summer Scholar por The Coase-Sandor Institute for Law \& Economics de la Escuela de Leyes de la Universidad de Chicago. Ha participado en el Annenberg-Oxford Media Policy Institute en la Universidad de Oxford, en el Fashion Law BootCamp en la Universidad de Fordham en New York y en la Summer Academy del World Trade Institute en Suiza. Profesor de la Maestría en Derecho de la Propiedad Intelectual y de la Competencia de la PUCP. Presidente de la segunda Comisión Permanente de Ética del Consejo Nacional de Autorregulación Publicitaria (CONAR). Correo: grodriguez@ rodriguezgarcia.pe

${ }^{* * *}$ Bachiller en Derecho por la Universidad del Pacífico. Diplomado en Hacking Marketing por el Instituto Peruano de Publicidad (IPP). Programa de Especialización en Comercio Electrónico y Marketing Digital por la Cámara Peruana de Comercio Electrónico (CAPECE). 


\section{Introducción}

Sostener que las reglas legales pueden generar consecuencias no pretendidas no es particularmente innovador. Pese a ello, día a día se siguen produciendo reglas orientadas a conseguir fines que no solo no se logran, sino que, además, se ven lesionados por las propias reglas legales producidas. En ese sentido, se ha señalado que "las políticas creadas para una serie de propósitos casi siempre crean una serie de resultados adicionales que no eran parte del plan original. Muy a menudo estas consecuencias no pretendidas son seriamente adversas" (Hall, 2014).

Las razones son múltiples. Errores, ignorancia o simplemente el deseo desesperado de lograr los objetivos rápidamente hasta el punto de omitirse posibles consecuencias adversas (Howard, 2007). Sea como fuere, tales consecuencias no pretendidas pueden incluso ser más graves que el propio problema que deseábamos solucionar como lo enseña el famoso caso de estudio del profesor Sam Peltzman en honor a quién se emplea también la frase "efecto Peltzman".

Como se sabe, el citado economista estudió las consecuencias no pretendidas de exigir el empleo de cinturones de seguridad en los vehículos. Dado que el empleo de cinturones de seguridad reduce el costo de manejar a gran velocidad, se produce el incentivo de adoptar menos precauciones lo cual, a su vez, incrementa el riesgo de producir accidentes. De esta manera, si bien los cinturones de seguridad pueden tener un efecto positivo si analizamos el impacto de la medida en las personas que se encuentran en el vehículo, la historia es dramáticamente distinta para los peatones que puedan verse involucrados en accidentes (Peltzman, 1975).

La existencia de consecuencias no pretendidas es inevitable. No todas las consecuencias no pretendidas, sin embargo, son indeseables. La famosa metáfora de la "mano invisible" de Adam Smith es un claro ejemplo de ello: que se obtenga el bienestar de todos a partir de actos individuales basados en el interés propio (Norton, 2002). No obstante, es frecuente que las consecuencias no pretendidas de la regulación sean más bien lamentables. Los incentivos de los individuos son complejos y una comprensión adecuada de éstos es necesaria si se quiere modificarlos en una dirección apropiada.

Comprender las motivaciones de los individuos sujetos a una regulación es indispensable para regular apropiadamente. Con acierto, entonces, se ha definido a la denominada "ley de las consecuencias no pretendidas" como:

“(...) lo que ocurre cuando un sistema simple trata de regular un sistema complejo. El sistema político es simple, opera con información limitada (ignorancia racional), horizontes de tiempo cortos, poca retroalimentación e incentivos mal alineados. La sociedad en contraste es compleja, en evolución, de elevada retroalimentación y conducida por incentivos. Cuando un sistema simple trata de regular un sistema complejo, usualmente se obtienen consecuencias no pretendidas" (Tabarrok, 2008).

Todo lo expuesto debería darnos luces sobre el cuidado especial que debe asumirse al regular. La retórica tradicional, sin embargo, encuentra cualquier aparente anomalía que no se condice con sus expectativas de lo que sería un mundo ideal y emplea la etiqueta de "falla de mercado". Así, los que apelan a esa retórica, encuentran "fallas de mercado" por doquier abriendo, lógicamente, un espacio inagotable para la "regulación correctora" (supuestamente). No existe controversia respecto de la posibilidad de que el mercado no actúe a la perfección (asumiendo en este momento que pueda producirse tal juico), pero tampoco debe existir controversia sobre las imperfecciones del mecanismo centralizado que algunos defienden tan apresuradamente. Cualquier "falla de mercado" (real o ilusoria) debe ser evaluada, de cara a su pretendida corrección, en contraste con los costos que la acción gubernamental implica. En ese sentido, más allá de la tarea sensible de determinar cuándo nos encontramos, realmente, ante un fallo de mercado (tarea que no emprendemos aquí) debe estar claro que, de encontrar uno, eso no es suficiente para justificar la acción correctora del Estado salvo que asumamos la perfección de la intervención gubernamental como premisa.

Nuestro enfoque se orienta a analizar las disposiciones referidas al llamado a revisión de productos defectuosos preguntándonos por las consecuencias que tales disposiciones generarán con el especial ánimo de detectar consecuencias no pretendidas negativas. Los individuos respondemos a incentivos y si queremos descubrir las consecuencias que una determinada regulación genera, resulta importante detenernos a examinar qué incentivos genera la regla legal que estamos empleando (Friedman, 2001). Como veremos en el presente trabajo, tenemos la impresión de que las reglas relativas a los llamados a revisión pueden generar consecuencias no pretendidas especialmente graves que debieran ser abordadas estableciendo una explícita inmunidad para los proveedores 
que cumplan diligente y proactivamente con el procedimiento establecido.

Las empresas enfrentan diversos riesgos al desarrollar su actividad económica. Un sistema de protección al consumidor sensato debe ser consciente de esos riesgos y atribuir responsabilidad únicamente en aquellos casos en los que se espere generar incentivos en los proveedores para adoptar un curso de acción que no genere un impacto negativo superior en los consumidores, por ejemplo, mediante el incremento de los precios de los productos o servicios. Este dato es importante porque, como alguno de nosotros ha insistido, no es posible concebir a los consumidores y a los proveedores como sujetos desconectados (Rodríguez García, 2013), esto es, como si los deberes impuestos a los proveedores se tradujeran exclusivamente en beneficios netos sin traslado de costo alguno.

Desplegar un llamado a revisión no es un proceso sencillo. La reparación o sustitución de los productos o los eventuales reembolsos hacia los consumidores pueden significar un impacto económico que, visto en conjunto con el posible impacto reputacional adverso, pueden condenar a la empresa a una irremediable salida del mercado. Al mismo tiempo, en términos de política pública, queremos que las empresas llamen a revisión a sus productos cuando sea necesario. Dicho en simple, reconocemos que el proceso puede ser genuinamente tortuoso, no obstante, queremos que los proveedores quieran pasar por dicho proceso pues éste viabiliza que se retiren los productos potencialmente dañinos para los consumidores.

La única forma de hacer que los proveedores quieran adoptar un llamado a revisión costoso y complejo es diseñar un procedimiento que ofrezca los incentivos correctos. Nuestra meta última es que los consumidores no se vean expuestos a productos potencialmente peligrosos o inseguros y la forma de lograrlo es fomentando la constante autoevaluación de los productos por quien sabe más sobre éstos. Un sistema de protección al consumidor que confiara exclusivamente en la autoridad competente para testear los productos de manera continua y administrar el retiro de los productos cuando sea necesario, devendría en un sistema de costos elevadísimos pues, como premisa inicial, exigiría de la autoridad un conocimiento profundo de cada producto puesto en el mercado.

En este caso, es especialmente palpable la importancia de trabajar las políticas de protección al consumidor sin sesgos anti-proveedor. No puede negarse, por ejemplo, que establecer reglas rígidas de atribución de responsabilidad pueden equivaler, en términos económicos, al empaquetamiento de seguros mandatorios en los productos con los consecuentes efectos en el precio que los consumidores pagan. Creemos que la retórica casi romántica de la visión tradicional de la defensa del consumidor debe ser reemplazada por un juicio inteligente sobre los fines que pretendemos y las mejores vías para lograr tales fines.

\section{Llamados a revisión: los objetivos generales}

Como cuestión previa, resulta importante destacar que no existe producto perfecto en el mercado. Para un proveedor, garantizar la perfección de un producto es un asunto riesgoso pues la propia calificación depende del individuo que aprecia el producto. La empresa, por cierto, tiene derecho a ofrecer el atributo que desee ofrecer con los costos que ello implique siendo los consumidores los que determinarán si vale la pena pagar por ese producto. Así, cuando una empresa como Starbucks ofrece rehacer el café hasta que el consumidor esté satisfecho, está autoimponiéndose un deber de perfección por el que los consumidores están dispuestos a pagar. Una cosa es que una empresa se imponga determinados estándares y otra, por cierto, que el sistema legal establezca los atributos del producto que ofrece el proveedor.

Pongámonos en los zapatos de una manufacturera de peluches: si los compradores esperan un producto sin falla alguna, la manufacturera diariamente tendría que enfrentarse a reclamos por fallas percibidas por los consumidores como, por ejemplo, la existencia de un pequeño desnivel entre la posición de los ojos de uno de los peluches o, por mencionar un juicio enteramente subjetivo, la supuesta suavidad insuficiente en el algodón. Estos reclamos no solo importan un elevado costo sino, como ya hemos visto, suelen verse reflejados en el precio de los productos con la consecuente restricción especial en quienes tienen menos recursos económicos.

Debe estar claro, como cuestión conceptual elemental, que la mística adecuada de la autoidentificación de riesgos se sostiene en un dato incuestionable: el nivel de seguridad óptimo viene establecido por el mercado y no por la autoridad de protección al consumidor. La paradoja de las reglas de protección al consumidor que se apoyan en la fijación de un estándar estatal relativo al producto o servicio ofrecido (cantidad de información estándar o, como en nuestro caso, seguridad estandarizada) es que están condenadas al fracaso y, usualmente, suelen 
tener efectos anticompetitivos (Dam, 1970). Si la agencia de competencia define un nivel de seguridad aplicable a todos los proveedores, el efecto sería el mismo que el de un acuerdo entre todos los proveedores pactando ofrecer un nivel de seguridad consensuado: excluir a aquellos proveedores que encuentren más costoso ofrecer un producto con ese nivel de seguridad tasado con el consecuente efecto en la reducción de la competencia y el potencial incremento de los precios. Lo único que cambia entre el acuerdo de los proveedores y la regla de protección al consumidor es que una viene dada por los agentes privados y la otra viene establecida por la regulación. Regulación anticompetitiva en defensa de los consumidores para perjuicio ineludible de los propios consumidores a los que se pretende proteger.

Muchas veces, las autoridades de protección al consumidor asumen equívocamente que el nivel eficiente de seguridad en un producto es el máximo posible o que el nivel eficiente de defectos reales o potenciales es cero. Los problemas asociados a esta línea de pensamiento son graficados en la siguiente cita: "(I)a respuesta simple de que todos los productos deben ser completamente seguros es ciertamente incorrecta. Los carros serían más seguros si fueran construidos como tanques y si no fueran tan rápido, pero esta seguridad mejorada se obtendría a un costo (...)" (Viscusi, 1991).

Ahora bien, siendo claro que el sistema de protección al consumidor no puede exigir la perfección de los productos y servicios que se ofrecen en el mercado, es sin duda importante establecer un mecanismo para permitir el retiro del mercado de aquellos productos que puedan tener defectos, en especial, cuando éstos se traducen en un importante riesgo a la seguridad o salud de los consumidores. La determinación de los casos en los que podemos enfrentar un "riesgo grave" depende de una valoración basada, fundamentalmente, en la cantidad de información que posee la autoridad competente por lo que, de ordinario, el diseño del procedimiento de llamado a revisión también debe generar incentivos para su empleo en aquellos casos en los que sea necesario. Ciertamente no es el objetivo del sistema fomentar llamados a revisión en escenarios superfluos.

Dado que son los proveedores los que cuentan con más información sobre sus productos, resulta deseable que sean éstos, con su conocimiento especial, los que asuman la tarea de conducir un permanente proceso de autoevaluación de su oferta. Será este proceso de autoevaluación el que permitirá descubrir eventuales riesgos no previstos o no previsibles al momento de ofrecer el producto para que, luego del eventual descubrimiento del problema, se ejecuten las acciones del caso para salvaguardar a los consumidores.

En estos términos, queda claro que un sistema de llamado a revisión no solo debe generar incentivos para que se reporte a los consumidores los defectos descubiertos sino, como aspecto de especial relevancia, debe incentivar también a los proveedores a efectuar el proceso de autoevaluación. Las reglas legales que penalizan al proveedor por advertir un riesgo no previsto desincentivan el proceso de autoevaluación traduciéndose en la subsistencia de productos defectuosos en el mercado.

De manera complementaria, debe reconocerse que el uso del producto revela información sobre eventuales riesgos que únicamente podrían haber sido identificados a un costo enorme (Ben-Shahar, 2006). Así, se ha señalado que "solo luego de que un producto es lanzado al mercado el fabricante recibe información detallada sobre los potenciales daños y riesgos". Es, en tal sentido, en interés de la sociedad en su conjunto, que podamos identificar todos esos riesgos lo antes posible lo cual exige de las autoridades la definición de las reglas que generen el incentivo apropiado en los proveedores de monitorear de manera adecuada el desempeño de los productos o servicios.

Según puede apreciarse, la notificación pública de un llamado a revisión es un anuncio formal que puede ser voluntario (el propio desarrollador del producto o el comerciante del mismo lo implementa) o mandatorio (a exigencia de la autoridad gubernamental) y que contiene usualmente información sobre la identidad de quien lo emite, el producto y el posible defecto o riesgo, acciones que pueden ser adoptadas por los consumidores, los lugares en los que el producto puede ser encontrado y a quien contactar en caso se necesite mayor información. Esta tarea de notificación suele implicar un proceso de organización bastante complejo que va de desde lo logístico hasta asuntos legales y financieros (Ahsan y Gunawan, 2014).

En general, las legislaciones emplean criterios diversos orientados a regular la responsabilidad de la empresa en el contexto de un llamado a revisión, variando desde el monto de la multa a la que se podría enfrentar el proveedor, así como penas asociadas a la demora en la implementación del retiro. Incluso podría pensarse en estrategias regulatorias en las que se les incentiva a las 
empresas a realizar dicha acción mediante una recompensa que las exonera de algún costo que de otro modo tendría que asumir (por ejemplo, costos del proceso). La asunción general es que los llamados a revisión son mecanismos positivos que protegen efectivamente a los consumidores.

Las industrias en las que normalmente se suelen implementar llamados a revisión son el sector farmacéutico, el automotriz y el de juguetes. Lo anterior se da por dos principales razones: la primera está relacionada con la especial sensibilidad de los productos ofrecidos en esos campos y, la segunda, tiene que ver con la complejidad que puede tener la detección de defectos dada la complejidad de los productos respectivos. Nótese que un error de manufactura o un atributo inseguro en el caso de los juguetes podría ser nefasto para la salud del niño que se encuentra jugando con él. Muchas veces ha ocurrido que se descubre un químico en la pintura de dichos juguetes que viene a ser tóxica para el niño (sobre todo considerando que el producto puede ser introducido en la boca), o incluso se descubre una pieza que puede ser peligrosa. En dichos casos, como ya ha ocurrido incontables veces en la industria de juguetes, es imprescindible que la empresa haga un llamado público para que todas las personas que han adquirido dicho producto lo devuelvan.

En 2016, se publicó el Decreto Supremo 050-2016-PCM que aprobó el extensamente denominado "Reglamento que establece el procedimiento de comunicación de advertencias y alertas de los riesgos no previstos de productos o servicios colocados en el mercado que afecten la salud y/o seguridad de los consumidores". En su artículo 1, se declara finalidad de dicho reglamento la regulación del procedimiento que los proveedores deben seguir para la eliminación o reducción de los riesgos no previstos cuando se afecte la salud o seguridad de los consumidores. Dicha finalidad se ve reforzada en el artículo 3 cuando, al precisar el alcance del reglamento, se insiste en que las disposiciones aplican a los proveedores que participan en el proceso de producción o comercialización de productos o servicios en los que se detecta la existencia de riesgos no previstos que afecten la salud o seguridad, así como, lógicamente, a las autoridades sectoriales y el propio INDECOPI en lo que toque a sus competencias.

Un detalle que merece comentario está referido al alcance del procedimiento pues, como se observa, éste se encuentra circunscrito a "riesgos no previstos". Esta delimitación no solo fluye claramente de los artículos ya aludidos, sino que, incluso, cuando en el artículo 8 se alude a las medidas que deben adoptarse, el reglamento insiste en que "cuando se verifique la existencia de riesgos no previstos para la salud y/o seguridad de los consumidores en productos o servicios colocados en el mercado, el proveedor debe adoptar de manera inmediata medidas razonables destinadas a eliminar o reducir dicho riesgo".
En general, el reglamento pretende desarrollar el mandato que ya el propio Código de Protección y Defensa del Consumidor recoge en su artículo 28 y que establece el deber del proveedor de adoptar medidas razonables para eliminar o reducir el riesgo de peligros cuando estemos frente a productos o servicios en los que: (i) se detecta la existencia de riesgos no previstos con anterioridad; o, (ii) se detecta la existencia de riesgos imprevisibles. Finalmente, y no menos importante, el artículo 28 prescribe que "tratándose de riesgos previsibles con anterioridad a su introducción en el mercado, la responsabilidad por la adopción de las medidas anteriores se entiende sin perjuicio de la responsabilidad administrativa". Dicha disposición nos permite arribar a la conclusión que, cuando estemos frente a riesgos no previstos o imprevisibles, si bien es responsabilidad del proveedor adoptar las medidas respectivas, opera una exoneración de responsabilidad administrativa pues, si así no fuera, resultaría absurdo estipular de manera explícita que cabe la posibilidad de atribuir responsabilidad administrativa en un supuesto particular-riesgos previsibles- cuando ésta existe también en los otros supuestos -riesgos no previstos o imprevisibles-.

Ahora bien, y aunque una discusión de este tipo probablemente extendería este trabajo de manera considerable, no podemos dejar de apuntar la paradoja de abordar desde la regulación mandatoria un procedimiento que debería ser voluntario. En efecto, siendo importante generar incentivos para que los proveedores retiren voluntariamente aquellos productos sobre los que entiendan que existe un riesgo, resulta genuinamente debatible que la implementación de un llamado a revisión a la luz del reglamento sea honestamente voluntaria (Bernstein, 2013). Así, aunque la expresión "Ilamado a revisión" alude típicamente a una decisión del proveedor respecto de su propio producto, quizás sea más honesto referirnos a un "mandato de revisión" en nuestro sistema de protección al consumidor. 


\section{Llamados a revisión: idas y venidas en la casuística peruana}

Puede resultar extraño sostener que el retiro de productos defectuosos del mercado tiene un lado oscuro. Sin duda, es deseable que los proveedores procedan al retiro inmediato de todo producto que puede conspirar contra la seguridad o salud de los consumidores y eso no debería merecer objeción alguna. Sin embargo, es en este punto en donde la casuística peruana revela que una concepción rígida de la responsabilidad administrativa conlleva consecuencias no pretendidas que vale la pena explicitar a modo de invocación dirigida a quienes día a día siguen bajo los efectos de la teoría tradicional que tanto se profesa sobre la protección al consumidor.

De modo general, nuestra advertencia tiene dos aristas: (i) si el sistema de llamado a revisión no confiere una inmunidad para los proveedores que lo ejecutan, se genera el incentivo perverso de no emplearlo dados los costos pecuniarios y reputacionales que suelen generar estos procedimientos. Evidentemente, si el proveedor no ejecuta el llamado a revisión, se mantiene el riesgo de afectación a la salud o seguridad de los consumidores y eso es precisamente lo que se quiere evitar; y, (ii) si el sistema de llamado a revisión obliga a los proveedores a padecer un procedimiento costoso y complejo y con la posibilidad de merecer denuncias o alguna investigación de oficio, se genera el incentivo a no realizar la autoevaluación que se estima deseable. En efecto, es la autoevaluación del producto la que permite descubrir riesgos no previstos de modo que un esquema excesivamente duro podría dar la señal de que la ignorancia implica más beneficios que costos.

El riesgo de crear una suerte de "efecto Peltzman a la peruana" se materializó en el 2012 con un muy cuestionable fallo de la entonces Sala de Defensa de la Competencia 2 (hoy, Sala Especializada en Protección al Consumidor) en el que se refiere abiertamente que "frente a los defectos de fábrica u otros defectos ocultos en el bien adquirido, el proveedor resultará responsable, aún cuando medie un periodo de garantía determinado y estos se hagan perceptibles con posterioridad" (Resolución 177-2012/SC2-INDECOPI). Una lectura de este pasaje impresiona de inmediato como una regla perversa: si el proveedor es responsable incluso cuando se descubra un "defecto oculto", ¿cuál sería el incentivo para descubrirlo?

Este mismo pronunciamiento, remata lo ya expuesto refiriéndose a las expectativas que supuestamente tendría un consumidor, en este caso, de un vehículo nuevo afirmando que "(...) también esperaría que cualquier pieza que deba instalarse en un componente fundamental del vehículo (como el acelerador), sea instalada y probada en éste al momento de su fabricación, siendo en esta etapa donde se pueda verificar la existencia de cualquier problema que pueda surgir, es decir, antes de su comercialización en el mercado".
Desde luego, INDECOPI está asumiendo que no deberían existir riesgos no previstos luego de la comercialización pues, como fluye claramente de la cita, la verificación de "cualquier problema que pueda surgir" tendría que producirse "antes de su comercialización en el mercado". Ahora bien, si fuera cierto que todos los posibles problemas se detectan antes de la comercialización, ¿cuál sería el sentido de que existan procedimientos de llamado a revisión? Es más, a la luz de lo expuesto en el fallo, ¿qué sentido tendría lo prescrito en el artículo 28 del propio Código al que ya hemos aludido anteriormente?

El incentivo obvio de una empresa para realizar llamados a revisión de forma inmediata, además de no sufrir daños reputacionales en la marca, viene sustentado en la posibilidad de incurrir en responsabilidad por la omisión de realizarlo o por la demora en su ejecución. Ante la posibilidad de evitar una contingencia legal grave, las empresas reaccionarán previsiblemente retirando los productos defectuosos o inseguros del mercado a fin de evitar este riesgo. Por el contrario, si la autoridad atribuye responsabilidad incluso cuando se advierte de la existencia de un defecto antes oculto, el valor del llamado a revisión se vería sensiblemente reducido incrementando las posibilidades de que los productos con riesgos potenciales se mantengan en el mercado.

En sentido similar, se ha señalado que:

"cuanto más severa y costosa es la responsabilidad atribuida, más renuente será el fabricante racional para realizar un recall de un producto que debería ser retirado de los anaqueles. La legislación de responsabilidad por productos defectuosos conspira contra la meta que se propone lograr de seguridad óptima" (Ben-Shahar, 2005).

Dado que el fallo de INDECOPI elevó los costos de hacer un llamado a revisión, era previsible que se generara una consecuencia que precisamente se quería evitar: que se omita la ejecución del llamado a revisión y que se descubran, como paso previo, riesgos ocultos en los productos.

Asimismo, el fallo asume que es posible detectar cualquier problema potencial en un 
producto antes de su comercialización lo cual es, en el mejor de los casos, simplemente ingenuo y, en el peor -aunque dramáticamente más realista- una premisa que puede generar, nuevamente, consecuencias no pretendidas genuinamente nefastas. En efecto, asumir que cualquier fallo potencial puede ser advertido antes de la comercialización del producto exigiría de la asunción de un costo extremo que ningún consumidor estaría dispuesto a asumir. ¿Se imagina el precio de un producto que ha tenido que ser analizado hasta el punto de arribar a la casi plena convicción de que no tiene ni tendrá problema alguno? La explicación es expresada de esta forma:

"(...) las firmas no hacen juicios arbitrarios respecto a que tan lejos deberían ir en términos de proveer seguridad a sus productos. El juicio es, de hecho, realizado por los consumidores a través de los precios que están dispuestos a pagar por seguridad adicional. Si los consumidores están informados de los riesgos de diseños alternativos de los productos y adoptan decisiones racionales, los precios que los consumidores estarán dispuestos a pagar reflejarán plenamente el valor que le confieren a la seguridad adicional. La seguridad sí tiene un valor y (...) ese valor es considerablemente elevado, aunque, no obstante, ello, sea finito" (Viscusi, 1991).

La doctrina tradicional suele tener serias dificultades para entender el funcionamiento del mercado en la práctica. Así, por ejemplo, se ha señalado que:

“(...) por más que al consumidor se le reponga el producto o se ejecute nuevamente el servicio, nada resarcirá o reparará los gastos y el tiempo invertido en reclamar, esperar la revisión del caso y tener que volver a acudir al establecimiento las veces que sean necesarias para encontrar una solución final y, por así decirlo, adecuada. Como lo es el caso de una prenda de vestir comprada especialmente para una ocasión (y que evidentemente se utilizará en otras), pero que tuvo que ser devuelta y cambiada por un defecto en particular" (Amaya, 2013).

Es evidente que para el consumidor no es lo mismo un producto que jamás desplegó un problema que un producto que despliega alguno y que debe, consecuentemente, ser reparado. Sin embargo, solo una apreciación superficial de la cuestión podría aconsejar que se atribuya responsabilidad por el solo hecho de que se haya evidenciado el problema. La retórica es engañosa: el punto no es que el consumidor prefiera un producto perfecto a uno reparado (que es obvio) sino que el consumidor no suele preferir el pago de un precio exacerbado como consecuencia del costo enorme de detección preventiva de cada posible problema que pueda suscitarse.

La regla, además, puede tener consecuencias indeseables en el mercado pues puede inhibir la entrada de muchos productos $y$, especialmente, podría inhibir la participación en el mercado de aquellos fabricantes con menor capacidad para trasladar los costos elevados al precio final del producto. Cuando se diseñan reglas legales, como ya insistimos en la introducción, deben analizarse las consecuencias posibles. Es sencillo reclamar que los medicamentos, por mencionar un ejemplo, sean probadamente seguros. Sin embargo, el tiempo que nos toma asegurar ello se traduce en tiempo en el que el fármaco no está en el mercado curando enfermos. Eso no significa que los medicamentos deban aprobarse a la ligera pero ciertamente la regla contraria, que deberíamos lanzarlos al mercado cuando exista convicción absoluta de que son $100 \%$ seguros, implica costos de oportunidad genuinamente elevados incluso en términos de vidas humanas.

El error estrepitoso del criterio sobre idoneidad en el caso ya mencionado era visible en muchos frentes. En particular, asumiendo el carácter bien intencionado del fallo, creemos que reveló una visión romántica (o ingenua) del proceso regulatorio. ¿Cómo podría la autoridad conocer lo que millones de consumidores querían en términos costo-beneficio? Se ha dicho, de manera precisa, que cuando los reguladores intentan maximizar un parámetro específico (por ejemplo, haciendo que ciertos productos sean más atractivos que otros $\mathrm{o}$, relevante a nuestro tema, elevando el nivel de seguridad hasta un punto arbitrariamente concebido) actúan como si los mercados fueran medios para generar los resultados que desea el regulador (Mufarrige y Zywicki, 2020).

Afortunadamente, la regla que el caso citado generó fue abandonada algunos años después. Así, en el año 2015, la Sala Especializada en Protección al Consumidor expresó que:

“(...) el sistema de protección al consumidor tiene por finalidad sancionar a aquellos proveedores que ponen a disposición de los usuarios productos o servicios defectuosos como también a aquellos que no cumplen sus expectativas de acuerdo a las condiciones ofrecidas; sin embargo, tal propósito surge en tanto exista y quede acreditada una falla o desperfecto y no puede servir como fundamento para sancionar a aquellas empresas que, por políticas para mejorar la calidad de los bienes que ofertan en el mercado, realizan llamados de carácter preventivos, buscando brindar un producto o servicio idóneo a sus clientes" (Resolución 2547-2015/SPC-INDECOPI).

El lector advertirá, no obstante, que, aunque se trata de un alejamiento saludable de la regla inicial, no deja de ser un pronunciamiento "tibio" en el que parecen dejarse muchas puertas abiertas para la 
atribución de responsabilidad. En efecto, el fallo alude a llamados a revisión que tengan por base "políticas para mejorar la calidad de los bienes que ofertan en el mercado" pero, de ordinario, el proveedor no llama a revisión sus productos porque quiera mejorar la calidad de lo que ya vendió, lo hace porque ha detectado que existe un riesgo potencial. Asimismo, cabe preguntarse qué ocurre si se determina que, en efecto, el riesgo era real y que el producto era genuinamente riesgoso para los consumidores pese a que ello no podía ser razonablemente conocido antes de su puesta en el mercado. Siguiendo la lógica del fallo, al estar acreditada la existencia del fallo o desperfecto, debería sancionarse al proveedor. Esa lógica no puede ser aceptada pues, en esos términos, el proveedor perdería incentivos para hacer llamados a revisión cuando tenga evidencias de que realmente existe un defecto y los implementaría únicamente cuando tenga sospechas y lo ejecute de manera preventiva.

Como se observa, el fallo parece sugerir que la inmunidad necesaria por efectuar un llamado a revisión está circunscrita a un campo bastante más pequeño del que incluso fluye del reglamento respectivo. Tal reglamento, vale decirse, establece deberes en los proveedores que pueden ser bastante costosos: (i) comunicar a la Dirección de la Autoridad Nacional de Protección al Consumidor sobre la existencia de riesgos no previstos; (ii) emitir la advertencia correspondiente comunicándosele a los consumidores sobre los peligros de los productos o servicios; y, (iii) disponer la sustitución, reparación, retiro del mercado $u$ otras medidas que mitiguen o eliminen el riesgo existente. Así, el procedimiento aplica a los escenarios de riesgos no previstos incluso cuando el riesgo efectivamente se materializa en un defecto del producto pues la regulación no hace distinción al respecto.

Por último, los llamados a revisión suelen implicar revelación de información al público. El sistema de advertencias y alertas vigente en Perú efectivamente contiene, como ya se ha visto, un deber de advertir a los consumidores que, cuando se trata de consumidores de posible individualización, puede expresarse en comunicaciones individuales tales como cartas, llamadas o correos electrónicos. Sin embargo, cuando ello no es posible, los proveedores deberán necesariamente emplear un medio de comunicación masiva de alcance nacional.

Evidentemente, difundir a los consumidores que existe un riesgo de defecto en el producto puede traducirse en una avalancha de reclamos y denuncias. Un sistema de llamado a revisión mal concebido reduce también los incentivos a su empleo al implicar la revelación de información pública sobre una situación no deseada por los consumidores. Precisamente por ello, conviene insistir nuevamente en que los proveedores requieren más que la insinuación de una posible exoneración de responsabilidad, sino una disposición expresa que, sin tapujo alguno, prescriba inmunidad para los proveedores que ejecuten de manera diligente y proactiva un llamado a revisión, sin perjuicio de que el proveedor tenga que aportar algún tipo de evidencia sobre la imposibilidad razonable de detectar preventivamente el riesgo.

\section{Llamados a revisión: comentarios finales}

De un lado, es evidente que los proveedores tienen incentivos para revelar información positiva sobre la seguridad asociada a sus productos con la finalidad de incrementar sus ventas. De otro lado, la revelación de información negativa asociada a dicha seguridad puede tener un impacto reputacional que afecte las ventas y que, incluso, podría comprometer la permanencia de la firma en el mercado. La posibilidad de que los consumidores puedan recompensar a los proveedores que comercializan productos seguros y que puedan castigar a los que comercializan productos inseguros depende fundamentalmente de la información que tengan a su disposición sobre la seguridad de tales productos y la capacidad de procesamiento de tal información.

Frente a la posibilidad de información negativa revelada en el mercado, las empresas debieran adoptar acciones orientadas a investigar permanentemente los riesgos derivados de sus productos a fin de implementar correctivos voluntarios antes que una noticia adversa se propale. No obstante, cuando la regulación no prescribe con claridad la inmunidad del proveedor que diligentemente conduce un llamado a revisión, se pueden producir dos efectos directos: (i) menor información adversa obtenida directamente por el proveedor lo cual inhibe el retiro voluntario de los productos que, en efecto, debieran ser retirados; y, (ii) la información que de forma preponderante subsiste en el mercado versa sobre información positiva dado que es la que incrementa ventas de modo que, previsiblemente, las decisiones de consumo se adoptan sobre-estimando la seguridad real de una diversidad de productos sensibles.

Normalmente, es en los campos de los automóviles, medicamentos y productos electrónicos en donde más se suele emplear el sistema de llamado a revisión. Sin embargo, 
debe notarse que ninguno de esos productos es particularmente exótico o extraño para los consumidores. Como regla general, existen incentivos débiles para incrementar la seguridad de los productos en aquellos casos en los que nos enfrentamos a productos de comercialización esporádica y muy especializada (Polinsky y Shavell, 2010). Por el contrario, cuando nos encontramos frente a productos comercializados de manera abierta, es razonable suponer que medidas de transparencia de la información generarán incentivos apropiados en los proveedores ante el riesgo de que se detecten fallos o defectos.

Un sistema de llamado a revisión inteligente debe promover la transparencia y no reducir los incentivos de los proveedores para descubrir riesgos ocultos. Henry Hazlitt, el autor del popular libro "Economics in one lesson", sostuvo que, al analizarse una propuesta o medida, debían rastrearse no solo los resultados inmediatos sino también los de largo plazo, es decir, no podíamos concentrarnos en las consecuencias primarias perdiendo de vista las secundarias (Hazlitt, 1979). El fallo de Indecopi del 2012 es un evidente ejemplo de lo que ocurre cuando se pierden de vistas las consecuencias no pretendidas. Si bien el fallo de 2015 avanza en la dirección correcta, consideramos que se queda "a medio camino" dejando espacios que, en la práctica, mantienen vigentes los eventuales incentivos perversos a los que hemos aludido en el presente trabajo.

Los llamados a revisión son procedimientos costosos. En efecto, la realización de un llamado a revisión implica costos directos e indirectos: los costos directos, se ha sostenido (McDonald, 2009), pueden ser divididos en tres tramos: (i) costos previos al llamado a revisión; (ii) costos de ejecución del Ilamado a revisión; y, (iii) costos posteriores al llamado a revisión. Dentro del primer grupo encontramos costos legales y de gestión del proceso de retiro de productos. En función a la magnitud del llamado a revisión, probablemente sea necesario que exista un equipo de trabajo que tenga por función analizar rápidamente la mejor forma de conducir dicho proceso. Los abogados deberán observar con detenimiento las garantías aplicables y las contingencias legales que pueden producirse como consecuencia del retiro de productos.

El proceso de llamado a revisión en sí mismo implica costos de notificación (informar a los consumidores que deben devolver sus productos mediante, por ejemplo, anuncios en medios de comunicación) y costos asociados a los remedios a implementarse (reparación o manufactura de productos sustitutos o de partes de reemplazo para los casos de componentes fallidos, entre otros). Finalmente, los costos posteriores al llamado a revisión suelen estar dados por la necesidad de recopilar y remitir información a las autoridades de consumo para el seguimiento correspondiente y, por cierto, costos de monitoreo de información para utilidad de la propia empresa (estructuración de garantías distintas en el futuro, por ejemplo).
Del lado de los costos indirectos, el más evidente e impactante es el referido a la pérdida de reputación. Cuando aludimos a la pérdida de reputación no solamente debemos considerar el impacto reputacional en el proveedor que hace el llamado a revisión, sino en las eventuales externalidades negativas que pueden sufrir proveedores competidores. No puede perderse de vista que los llamados a revisión pueden significar un desgaste reputacional que podría ser extendido hacia otros productos que tenga la marca no necesariamente de la misma línea. Asimismo, los consumidores podrían inferir un mensaje respecto de la seguridad del "tipo" de producto afectándose a la industria en su conjunto.

Este último punto debe ser considerado. Así, se ha dado cuenta de que el llamado a revisión sobre los Ford Pinto en 1978 (que le habría costado a la empresa unos veinte millones de dólares después de impuestos) afectó no solo a ese modelo de automóvil sino a los modelos similares de empresas competidoras (Nash, 2010). Los consumidores pueden interpretar la señal generada por el llamado a revisión como un mensaje no focalizado en el producto específicamente afectado generando un impacto reputacional en terceros (y un incremento posible de precios para los consumidores de productos que no fueron llamados a revisión).

Diseños pobres o apresurados del sistema de alertas y advertencias y, en general, del procedimiento de llamado a revisión, pueden generar consecuencias no deseadas. Creemos que una lectura adecuada del artículo 28 del Código apunta hacia el modelo que estamos defendiendo, pero los pronunciamientos ya aludidos han sembrado innecesarias dudas sobre aquello que no debería admitir controversia: si un proveedor ejecuta apropiadamente un llamado a revisión cuando identifica un posible riesgo no previsto o no previsible, debe merecer una inmunidad plena. Eso, está claro, no puede ser interpretado como una licencia para poner productos en el mercado con riesgos que debieron ser razonablemente previstos; sin embargo, es el proveedor quien tiene el conocimiento necesario para sustentar si tal previsión realmente no era posible. 
Adicionalmente, el propio reglamento, al ocuparse de las funciones de la Dirección de la Autoridad Nacional de Protección al Consumidor, agrega, entre las mencionadas:

“(s)uministrar información a la Gerencia de Supervisión y Fiscalización y a la Comisión de Protección al Consumidor respectiva, en caso de detectar una posible afectación de los consumidores debido a la falta de idoneidad de los productos que representen riesgos en la seguridad de los consumidores, o a las omisiones al deber de información, reporte, reposición, mitigación $\mathrm{y}$ advertencias que pueda haber generado determinado proveedor en el mercado".

Esta mención pareciera sugerir que, si el riesgo posible se materializa en una falta de idoneidad, podría abrirse una investigación en perjuicio del proveedor. El reglamento, en su artículo 17, se limita a una escueta disposición que estipula: "(I) a observancia de lo indicado en el presente Reglamento será tomada en cuenta por los órganos competentes del Indecopi a efectos de evaluar el cumplimiento de lo dispuesto en el artículo 28 del Código". Nos parece, como ya debiera ser evidente a estas alturas, una estipulación insuficiente.

La tentación de asegurarle al consumidor la mayor seguridad puede explotarle en la cara al propio consumidor (y a la autoridad). Los consumidores, de ordinario, no conocen profundamente sobre la seguridad del producto que adquieren y lo cierto es que tampoco hace sentido que inviertan en una indagación al respecto si uno presta atención a la cantidad de accidentes reportados como consecuencia de riesgos originalmente no previstos. En aquellos casos en los que pueda ser más trascendente, como un vehículo, la reputación del proveedor es especialmente importante de modo que, como generalidad, existen incentivos orientados a resguardar la percepción positiva que se tiene de la marca.

Sería interesante tener una cifra sobre el porcentaje de consumidores peruanos que devuelven el producto al proveedor ante un llamado a revisión para conocer el grado de efectividad del sistema. En el 2010, Consumer Reports dio cuenta de una encuesta en la que aproximadamente el $25 \%$ de encuestados se tomó la molestia de investigar si el producto adquirido había sido materia de un llamado a revisión y, de ese porcentaje, apenas un aproximado del $30 \%$ adoptó alguna medida (Koeppel, 2012). Si las cifras de respuesta son similares o inferiores en Perú, debería ser ese un llamado de atención empírico sobre los resultados de la regulación peruana sobre la materia.

Los proveedores no ofrecen cualquier seguridad, ofrecen en un mercado competitivo la seguridad por la que los consumidores están dispuestos a pagar (Ramseyer, 2012). Ninguna política sensata de protección al consumidor puede sostenerse sobre la base de la ingenua creencia de que las reglas protectivas no generan costos que los consumidores asumen. Por eso, no es posible construir una regla que exija de los proveedores poner un producto absoluta y probadamente seguro en el mercado (en el sentido de exento de riesgo algún) ni puede reducir los incentivos para detectar y reportar los riesgos que ciertamente podrían presentarse. Como si todo lo dicho no fuera suficiente, también resulta crucial determinar si la regulación peruana resulta más o menos compatible con regulaciones foráneas pues la diversidad regulatoria podría incrementar los costos de un llamado a revisión que trasciende fronteras nacionales. Aunque la tentación punitiva del Estado se vea insatisfecha, debe ser contenida en aras de conseguir la meta que deseamos: facilitar el retiro de aquellos productos que conspiran contra la salud y seguridad de los consumidores.

\section{Referencias bibliográficas}

Ahsan, Kamrul y Gunawan, Indra (2014). Analysis of Product Recalls: identification of recall initiators and causes of recall. Operations and Supply Chain Management, Vol. 7, (3).

Amaya, Leoni (2013). La muerte del deber de idoneidad. Diálogo con la Jurisprudencia, 173, febrero.

Ben-Shahar, Omri (2005). How liability distorts incentives of manufacturers to recall products. Law and Economics Working Papers. University of Michigan Law School.

(2006). The (legal) pains of Vioxx: why product liability can make products more dangerous. The Berkeley Electronic Press, Economist Voice.

Bernstein, Anita (2013). Voluntary recalls. The University of Chicago Legal Forum, 1-10.

Dam, Kenneth W. (1970). Consumer protection: an overview. Antitrust Law Journal, Vol. 39, 4, Anuual Mettings.

Friedman, David (2001). Law's order: what economics has to do with law and why it matters. Princeton University Press.

Hall, Thomas E. (2014). Aftermath. The Unintended Consequences of Public Policies. Washington D.C.: Cato Institute.

Hazlitt, Henry (1979). Economics in one Lesson. New York: Arlington House.

Howard, Margaret (2007). The law of unintended consequences. Southern Illinois University Law Journal, Vol. 31. 
Koeppel, Dan (21 de junio de 2012). Why product recalls make you less safe. Popular Mechanics.

McDonald, Kevin M. (2009). Do auto recalls benefit the public? Regulation. Washington D.C.: Cato Institute.

Mufarrige, Christopher y Zywicki, Todd J (2020). Simple rules for a complex regulatory world: the case of financial regulation. George Mason University Law \& Economics Research Paper Series 20-10.

Nash, Betty Joice (2010). Markets for safety: Product recalls yield mixed effects on firms. Region Focus, Second Quarter.

Norton, Rob (2002). Unintended consequences. The Library of Economics and Liberty.
Peltzman, Sam (1975). The Effects of Automobile Safety Regulation. Journal of Political Economy. The University of Chicago Press, Vol. 83,4 .

Polinsky, A. Mitchell y Shavell, Steven (2010). The Uneasy Case for Products Liability. Harvard Law Review, Vol. 123.

Ramseyer, J. Mark (2012) Products liability and product safety: Japan and the U.S., John M. Olin Center for Law, Economics and Business, Harvard Law School, Discussion Paper 714.

Rodríguez García, Gustavo (2013). El consumidor en su isla: una visión alternative del sistema de protección al consumidor. Lima: Universidad del Pacifico.

Tabarrok, Alexander (2008). The law of unintended consequences. Marginal Revolution Blog.

Viscusi, W. Kip (1991). Reforming products liability. Harvard University Press. 